\title{
A EDUCAÇÃO VOLTADA PARA O EMPREENDEDORISMO: UM LEVANTAMENTO DO DEBATE ACADÊMICO
}

\author{
Marcelo de Amorim Pandolfi ${ }^{1}$ \\ Instituto Federal de Educação, Ciência e Tecnologia do Espírito Santo (Ifes) \\ Roseli Esquerdo Lopes ${ }^{2}$ \\ Universidade Federal de São Carlos (UFSCar)
}

\section{RESUMO}

Este artigo resulta de uma pesquisa que analisou teses e dissertações que se debruçaram sobre o empreendedorismo na educação, fruto de um levantamento realizado em julho de 2012, no Banco de Teses da Capes. Objetiva verificar se os trabalhos que defendem a inserção do empreendedorismo no ambiente acadêmico apresentam um debate, no sentido da discussão de um ponto de vista e do diálogo, com aqueles que questionam tal posição. Considera que as teses e dissertações analisadas, que advogam em benefício do ensino do empreendedorismo, partem da premissa, disseminada por alguns dos principais expoentes com relação ao tema, de que o empreendedorismo é um instrumento essencial para a diminuição das desigualdades sociais. Esses estudos acabam assumindo, ideologicamente, na maioria dos casos, a validade do conceito como um dogma, sem dialogar com aqueles outros que questionam os fundamentos sobre os quais assentam suas proposições. Também verifica que não foram encontradas diferenças significativas na abordagem do tema, entre os que defendem os benefícios de uma educação empreendedora, mesmo quando as pesquisas partiram de diferentes áreas do conhecimento, e que os poucos trabalhos que procuram questionar tal discurso provêm, principalmente, da área de Educação.

Palavras-chave: Educação brasileira. Educação e empreendedorismo. Educação e pesquisa.

\section{EDUCATION FOR ENTREPRENEURSHIP: A SURVEY OF THE ACADEMIC DEBATE}

\begin{abstract}
This article is the result of a research that has examined theses and dissertations that were the focus of entrepreneurship education, the result of a survey conducted in July 2012, in Capes' theses database. It aims to verify if the works that support the insertion of entrepreneurship in academic environment present a debate, in terms of a point of view discussion and dialogue with those who question such position. It considers that the thesis and dissertations that were analyzed, which advocate in the benefit of the entrepreneurship teaching, based on the premise, disseminated by some of the main exponents related to the theme, that entrepreneurship is an essential tool for the reduction of social inequalities. Ideologically, these studies eventually assume, in most cases, the validity of the concept as a dogma, with no dialogue to those others who question the fundamentals on which their propositions are based. It also checks that significant differences were not found in the theme approach, between those who advocate the benefits of a entrepreneurial education, even when the research started from different areas of knowledge, and that few works that try to find question such discourse come, mainly, from education area.

Keywords: Brazilian education. Education and entrepreneurship. Education and research.
\end{abstract}




\section{INTRODUÇÃO}

Há um tempo para se admirar o encanto e o poder persuasivo de uma idéia influente, como há um tempo para se temer que ela nos sufoque. $\mathrm{O}$ tempo para nos preocupar ocorre quando a idéia se expandiu a tal ponto que nem sequer a notamos e tão profundas se tornam suas raízes que nada mais representa do que o senso comum. Quando as objeções já não são respondidas, pois nunca mais foram levantadas, perdemos seu controle: não sabemos como ela nos pegou.

Alfie Kohn (1998, p. 17).

Nos últimos 20 anos, o empreendedorismo foi amplamente divulgado no Brasil e alcançou uma posição de destaque em nossa sociedade. Sendo assim, ultimamente, por todos os lados, há centenas de instituições e escolas propagando valores como autonomia, independência e geração de riqueza, motivando inúmeros indivíduos com a máxima "seja o seu próprio patrão".

Neste trabalho, adotou-se, para fins de análise, o conceito de empreendedorismo propagado pelos seus principais expoentes no Brasil, Dornelas (2008) e Dolabela (1999, 2008). Conforme Dornelas (2008, p. 22), "Empreendedorismo é o envolvimento de pessoas e processos que, em conjunto, levam à transformação de idéias em oportunidades. E a perfeita implementação destas oportunidades leva à criação de negócios de sucesso". Já para Dolabela (2008, p. 24), trata-se de "[...] um termo que implica uma forma de ser, uma concepção de mundo, uma forma de se relacionar".

Para aquele que empreende, o empreendedor, há inúmeras definições. Enquanto Birley e Muzika (2001), Maximiano (2006) e Mirshawka e Mirshawka Jr. (2003) destacam a atitude realizadora do empreendedor, Filion (1999) enfatiza o seu caráter visionário, e Dornelas (2008) o enxerga como uma pessoa diferenciada, detentora de uma motivação singular, apaixonada pelo que faz e desejosa de reconhecimento e admiração. Chiavenato (2004), por sua vez, considera-o um herói do mundo dos negócios, pois ele geraria empregos, incentivando o crescimento econômico de um país.

De fato, hoje, parece que não há quem ainda não tenha ouvido falar sobre empreendedorismo. Entretanto, apesar da intensa força a favor de uma atuação indiscriminada do empreendedorismo, já existem algumas poucas vozes dissonantes quanto a essa questão na educação. Nesse sentido, se, por um lado, o levantamento da literatura acadêmica realizado para a elaboração deste texto deixou claro que não faltam estudos dogmatizando a formação para o empreendedorismo, por outro, mostrou igualmente que é incipiente a produção científica que trata do assunto, tomando-o sob um ponto de vista mais crítico.

Os defensores do empreendedorismo declaram que ele é essencial para a geração de riquezas dentro de um país, contribuindo para a diminuição das desigualdades sociais, promovendo o crescimento econômico e melhorando as condições de vida da população por meio da geração de empregos e distribuição de renda (DORNELAS, 2008; DOLABELA, 1999; CHIAVENATO, 2004). Seus críticos afirmam que os valores do empreendedorismo propagam o individualismo e a competição, disseminando a ideia de que o sucesso ou o fracasso econômico e social é produto da mentalidade e do comportamento individual das pessoas (DIAS, 2006; LIMA, 2008; DREWINSKI, 2009). Além disso, de acordo com Lima (2008), o discurso empreendedor exclui dos trabalhadores, principalmente dos não qualificados, a garantia de realização profissional e ascensão social pela via do emprego formal. 
O problema central sobre o qual se debruçou este trabalho refere-se ao empreendedorismo inserido na educação e surgiu da percepção de que existe uma abundância de pesquisas acadêmicas brasileiras que fazem apologia ao tema e um número restrito que critica essa posição. Sendo assim, este texto objetiva verificar se as teses e dissertações que defendem a inserção do empreendedorismo no ambiente acadêmico apresentam um debate, no sentido da discussão de um ponto de vista e do diálogo, com aquelas que questionam tal posição. Entende-se que esse diálogo é imprescindível na discussão científica, como pode ser observado em Gramsci (1978, p. 31):

Na colocação dos problemas histórico-críticos, não se deve conceber a discussão científica como um processo judiciário, no qual há um réu e um promotor, que deve demonstrar por obrigação que o réu é culpado e digno de ser tirado de circulação. Na discussão científica, já que se supõe que o interesse seja a pesquisa da verdade e o progresso da ciência, demonstra ser mais avançado quem se coloca do ponto de vista segundo o qual o adversário pode expressar uma exigência que deva ser incorporada, ainda que como um momento subordinado, na sua própria construção. Compreender e valorizar com realismo a posição e as razões do adversário (e o adversário é, talvez, todo o pensamento passado), significa estar liberto da prisão das ideologias (no sentido pejorativo, de cego fanatismo ideológico), isto é, significa colocar-se em um ponto de vista crítico, o único fecundo da pesquisa científica.

As teses e dissertações aqui analisadas foram encontradas e selecionadas no Banco de Teses da Coordenação de Aperfeiçoamento de Pessoal de Nível Superior (Capes), em julho de 2012. Buscou-se, pelo critério "assunto" e pelo parâmetro "todas as palavras", as expressões "educação e empreendedorismo" e "ensino e empreendedorismo", tendo-se encontrado, respectivamente, um resultado de 246 e 232, totalizando 478 trabalhos. Desses, 110 apareceram em ambas as buscas, restando um universo de 368 teses e dissertações aptas para análise.

Para este estudo, a amostra foi composta pela leitura dos resumos das 368 teses e dissertações, que foram classificadas como: apologética, crítica ou sem foco. Entendeu-se por "sem foco" aquelas que não abordavam diretamente o empreendedorismo inserido no contexto acadêmico, mesmo nos casos em que apresentavam uma dimensão crítica sobre o tema.

Dentre aquelas classificadas como críticas, somente as que contivessem, em seus títulos, uma combinação da palavra empreendedorismo (ou derivação dela) com os termos educação, ensino, emprego, desemprego ou trabalho (ou derivações deles) foram selecionadas. Como resultado, obteve-se uma amostra de oito trabalhos.

Para equalizar a amostra, diante de mais de uma centena de pesquisas apologéticas, isto é, que apontam para os benefícios de uma educação voltada para o ensino do empreendedorismo, também foram escolhidos, de forma não probabilística intencional, oito trabalhos provenientes de diferentes áreas de conhecimento (Administração, Educação, Engenharia de Produção) que analisavam distintos níveis e modalidades de ensino.

A seção a seguir apresenta as teses e dissertações que defendem a inserção do empreendedorismo no ambiente educacional; posteriormente, são descritos os trabalhos que possuem uma visão crítica sobre a educação voltada para o empreendedorismo. 


\section{A SOLUÇÃO PELA VIA DA EDUCAÇÃO PARA O EMPREENDEDORISMO}

D'Alberto (2005), em sua dissertação de mestrado, pesquisou a existência e o enfoque do tema empreendedorismo nos cursos de Turismo nas instituições de ensino superior do Estado de Santa Catarina.

Dos 30 cursos identificados pela autora, apenas 13 possuíam uma disciplina específica sobre empreendedorismo na grade curricular ou esse enfoque em alguma ementa. Observou-se, então, que mais da metade dos cursos não tinha enfoque no empreendedorismo, chegando esse número a $73 \%$, se forem considerados aqueles que não possuíam uma disciplina específica. Analisando esse panorama, D'Alberto (2005, p. 138) concluiu que essa é uma "[...] clara evidência da necessidade de estudos em relação ao ensino do empreendedorismo nos cursos de turismo".

Inicialmente, a autora analisou as grades curriculares e ementários dos cursos, além das Diretrizes Curriculares Nacionais. Em uma segunda fase, aplicou um questionário aos coordenadores de curso e a um professor de cada uma das 13 instituições pesquisadas. A autora caracterizou os coordenadores e docentes quanto à formação acadêmica recebida e identificou o entendimento desses profissionais sobre o ensino do empreendedorismo e sua relação com o curso de Turismo. Após a análise dos dados, trabalhou com uma abordagem qualitativa, "Grupo de Foco", com os respondentes que demonstraram maior conhecimento sobre o assunto.

D'alberto (2005, p. 185) concluiu que o enfoque do empreendedorismo nos cursos de Turismo catarinenses ainda não está consolidado, sendo necessária a alteração das grades curriculares "[...] para que se possa de fato imprimir a importância que o ensino do empreendedorismo traz para os acadêmicos e, portanto, futuros turismólogos". Cabe assinalar que nenhum coordenador ou docente chegou a questionar a validade ou o significado de uma educação empreendedora para os futuros profissionais.

Também em uma dissertação de mestrado, Pavani (2006) se dedicou a avaliar a importância e a eficácia dos princípios fundamentais do empreendedorismo empresarial no curso Técnico em Agroindústria, como alternativa para a geração de ocupação e renda. Para tanto, partiu da hipótese de que o empreendedorismo e a educação para o empreendedorismo são uma solução para o desemprego.

Apoiado nas mudanças ocorridas no mundo do trabalho e nos atuais padrões assumidos pelo processo de industrialização, Pavani (2006) alega que as escolas devem preparar seus alunos para essa nova realidade e, nessa conjuntura, o empreendedorismo surge como uma resposta para acompanhar tais mudanças.

Comungando com autores como Fernando Dolabela e Louis Jacques Filion, Pavani (2006, p. 37) também afirma que a "pedagogia empreendedora" está vinculada à liberdade de escolha e ainda traz consigo a possibilidade de "realizar sonhos":

A Pedagogia Empreendedora é uma estratégia destinada a dotar o indivíduo de graus crescentes de liberdade para fazer sua escolha, cuja metodologia baseia-se em duas perguntas: qual é o seu sonho e o que você pode fazer para realizá-lo?

Após sublinhar os benefícios da "pedagogia empreendedora", Pavani (2006) enfocou o seu objeto de estudo: os egressos do curso Técnico em Agroindústria da Escola Agrotécnica Federal de Barbacena, residentes no município de Barbacena e região. Assim, com o objetivo de descobrir se os egressos atuavam no mercado de trabalho agroindustrial 
e se o perfil formado seria suficiente para ingressar nesse setor, o autor enviou um questionário para 75 egressos, composto por seis perguntas fechadas e um espaço para "sugestões".

Mesmo que, aparentemente, as perguntas de Pavani (2006) induzissem à ideia do empreendedorismo como solução para a entrada desses técnicos no mercado agroindustrial $^{3}$ - e os egressos não pareceram discordar totalmente dessa afirmação -, as "sugestões" coletadas no questionário apontaram para outras direções: $15 \%$ estágio remunerado, $15 \%$ mais visitas técnicas, $20 \%$ mais aulas práticas, $33 \%$ empreendedorismo, $17 \%$ não opinaram. Pode-se perceber, então, que, na opinião dos egressos pesquisados, o empreendedorismo não seria o único caminho para garantir a sua entrada no mercado de trabalho.

Com os dados coletados, Pavani (2006) conseguiu responder a uma de suas perguntas, isto é, se os egressos atuavam no mercado de trabalho agroindustrial (de fato, dos 41 questionários respondidos, apenas um egresso confirmou atuar no setor). ${ }^{4}$ Contudo, observando-se as respostas obtidas pelo questionário, percebeu-se que é difícil para o autor avaliar a importância e a eficácia do empreendedorismo como alternativa para a geração de ocupação e renda no curso analisado.

Em sua tese de doutorado, Pedro (2007), por seu turno, procurou construir uma proposta pedagógica para o desenvolvimento de características empreendedoras em crianças do ensino fundamental, integrando os conceitos de empreendedorismo, desenvolvimento de competências e o projeto político-pedagógico nesse nível de ensino. A pesquisa foi realizada pelo Laboratório de Empreendedorismo do Curso de Engenharia de Produção da Universidade Federal de Santa Catarina, a pedido de uma escola privada, com unidades nas Regiões Sul e Sudeste do Brasil, que também financiaram o projeto.

Depois do levantamento da literatura, a autora realizou entrevistas não estruturadas e um "treinamento" com os professores da disciplina Empreendedorismo e com o coordenador de ensino. Em seguida, construiu a sua proposta e aplicou o modelo aos discentes das quintas, sextas e sétimas séries da escola em questão, totalizando 4.197 alunos.

Para a autora, o modelo proposto visa à preparação dos alunos para o mercado de trabalho e para a vida, não se restringindo a uma formação relacionada com negócios e mercado competitivo. Ainda, segundo Pedro (2007, p. 70),

[...] é importante salientar a preocupação da presente pesquisa em relação à formação do indivíduo, de sua cultura, valores e regras. A idéia principal não é apenas mostrar a realidade do empreendedor e do mundo do consumismo, mas desenvolver habilidades que possibilitarão um futuro profissional, sem com isso desrespeitar a maturidade psicológica dos discentes.

A autora alegou ter alcançado os objetivos propostos, embora não seja possível confirmar se o modelo, realmente, fortalece a cultura empreendedora de uma determinada região porque, como ela mesma advertiu, seria necessário acompanhar os alunos no decorrer da sua vida acadêmica e profissional.

Não obstante Pedro (2007, p. 107) afirmar que, em seu modelo, “[...] o foco foi, principalmente, na construção de um indivíduo ético que possa agir pautado em valores e no respeito ao próximo e não somente nos aspectos relacionados com os negócios e o mercado competitivo", a mensagem que permaneceu foi a suposta inexorabilidade do 
sistema capitalista atual e a consequente necessidade de preparação de empreendedores desde a mais tenra idade.

Baseando-se em sua vivência nas discussões e formulações de políticas públicas voltadas para o campo da educação empreendedora, Leal (2009), em sua dissertação de mestrado, investigou as ações educacionais e a contribuição do Sistema Brasileiro de Apoio a Micro e Pequena Empresa (Sebrae) para o aumento da capacidade de empreender de jovens e adultos. A abordagem foi descrita pelo autor como qualitativa, utilizando fontes bibliográficas e documentais, especialmente, os registros do Sistema Sebrae.

Embora Leal (2009) não faça uma reflexão acerca do discurso do empreendedorismo e já parta do pressuposto de que o empreendedorismo é um caminho viável para contornar o problema do desemprego, ele fez referência ao trabalho de Souza (2006), que criticou o discurso do empreendedorismo na educação, concluindo, contudo, que:

Da sua abordagem - ainda que questionável - ressalta uma advertência pertinente aos interessados em estudos nessa área, quanto ao discurso eivado de ideologia compatível com o pensamento econômico de que o mercado tudo regula, e que culmina por atribuir à vítima a culpa pelo seu próprio insucesso (LEAL, 2009, p. xxv).

Dada a formação em Pedagogia do autor, poderia se esperar uma discussão um pouco mais intensa com o trabalho de Souza (2006) ou, ao menos, que se explicitasse o que torna a abordagem de Souza (2006) questionável. Por que Leal (2009), aparentemente, discorda de Souza (2006), mas, ao mesmo tempo, afirma existir uma "advertência pertinente" em sua abordagem, quando essa advertência é, na verdade, uma crítica contundente à educação empreendedora?

Leal (2009) concluiu que as atividades desenvolvidas pelo Sebrae têm um amplo alcance, especialmente por intermédio do ensino a distância, e que as ações educativas propostas pelo Sebrae podem estar contribuindo para o aumento de sobrevivência das empresas. Porém, o próprio autor alerta que a segunda afirmação precisa de uma investigação mais acurada e, por fim, afirmou:

Tudo isso só comprova o acerto da política do Sebrae para a Educação Empreendedora, [...] que é disseminar entre milhões de pessoas jovens e adultas, a cultura do empreendedorismo. Esta é a marca da Instituição e o que a faz tornar-se conhecida e reconhecida na comunidade pelo trabalho que realiza (p. cxl-cxli).

Cabe acrescentar que Leal (2009) é o único autor, dentre os apresentados nesta seção, que, ao menos, fez referência a um trabalho que critica a adoção da educação empreendedora.

Muito próximo a Pavani (2006), Senna (2010) se propôs a analisar, em sua dissertação de mestrado, a importância e a necessidade da associação do ensino agrícola ao desenvolvimento de comportamentos empreendedores no curso Técnico em Agropecuária do Campus de Alegre, do Instituto Federal de Educação, Ciência e Tecnologia do Espírito Santo (Ifes).

Após discorrer sobre a literatura acerca do empreendedorismo e educação empreendedora, Senna (2010) afirmou que o ensino empreendedor é capaz de despertar o desejo pelo aprendizado, traz confiança no potencial criador e realização profissional. 
Apontou ainda o ensino do empreendedorismo como elemento fundamental contra o desânimo e o desestímulo entre os alunos e como um instrumento poderoso na busca da transdiciplinaridade na prática escolar.

Senna (2010) aplicou dois questionários, com perguntas fechadas e abertas, enfocando o corpo discente e o corpo de servidores (docentes e corpo técnico-pedagógico), a fim de conhecer, principalmente, o nível de compreensão dos entrevistados sobre o empreendedorismo e o número dentre eles que acredita nos benefícios da educação empreendedora aliada ao ensino agrícola. Propôs-se também a verificar o papel da escola no processo de criação de condições para o desenvolvimento de comportamentos empreendedores, além de diagnosticar o nível de desinteresse dos alunos pelos estudos e a sua capacidade individual de realização profissional.

Feita a análise das respostas obtidas, o autor afirmou que há um razoável ou bom conhecimento sobre o que é o empreendedorismo entre os professores e o corpo técnicopedagógico, situação inversa daquela encontrada entre os discentes:

Comprovou-se que a maioria dos membros da comunidade pesquisada não sabe o que é o empreendedorismo, com a quase totalidade dos discentes possuindo total desconhecimento sobre o assunto e com os docentes e o corpo técnico-pedagógico possuindo conhecimento razoável ou bom. Esse aspecto demonstra a gravidade do problema, considerando que o conhecimento não é repassado aos alunos e que conhecer o empreendedorismo é fundamental para que se pratiquem propositadamente comportamentos empreendedores, como atestam autores diversos (SENNA, 2010, p. 54).

Diante dessa situação, o autor questionou o motivo pelo qual os professores não estão repassando esse conhecimento aos alunos, já que, para ele, "[...] o caminho para se minimizar os problemas é, indubitavelmente, a disseminação da cultura empreendedora no universo escolar" (SENNA, 2010, p. 49).

Neves (2010), em sua pesquisa com os egressos do curso Técnico em Agropecuária do Campus Januária, do Instituto Federal de Educação, Ciência e Tecnologia do Norte de Minas Gerais (IFNMG), discutiu a formação empreendedora recebida pelos discentes dessa instituição. Para tanto, o autor mencionou ter verificado se as estratégias e práticas metodológicas utilizadas no curso contribuíram para o desenvolvimento de competências e habilidades empreendedoras.

Como resultado da análise do projeto pedagógico e da matriz curricular do curso, Neves (2010) afirmou que o assunto é tratado de forma superficial e estanque, faltando uma integração com as outras disciplinas. $\mathrm{O}$ autor aplicou um questionário a um grupo de 36 egressos, com o intuito de conhecer o perfil desses ex-alunos e levantar dados sobre a participação do IFNMG na formação empreendedora, concluindo que a formação empreendedora recebida era insuficiente e se encontrava desarticulada da realidade socioeconômica da região. Para Neves (2010, p. 38), na verdade, não havia uma formação empreendedora, mas apenas "[...] pequenas ponderações do que vem a ser empreendedorismo e sua importância social e econômica".

Neves (2010), como os autores apresentados nesta seção, também não problematizou, em sua dissertação de mestrado, o discurso empreendedor. Ao contrário, ele o apresentou como fundamental diante da conjuntura econômica atual. 
Silva (2010), por sua vez, teve por objetivo avaliar o ensino do empreendedorismo nos cursos de Administração de Empresas das Instituições de Ensino Superior do Ceará. O autor, já no resumo da sua dissertação de mestrado, buscou elucidar o seu ponto de vista:

Justifica-se a sua elaboração diante da relevância do empreendedorismo como fator de superação da realidade econômica brasileira, desigual e injusta, e do papel das IES na construção de uma nova realidade em que cada jovem, egresso de seu ambiente, possa encontrar um espaço na sociedade para desenvolver suas potencialidades (SILVA, 2010, p. 9).

Perante tal justificativa, não há dúvidas de que Silva (2010) qualificou, a priori, a educação empreendedora como uma estratégia para os jovens, diante da realidade econômica brasileira, capaz de promover uma sociedade mais justa e igualitária.

A pesquisa foi realizada a partir de uma abordagem qualitativa, dividida em duas fases. Depois da revisão da literatura e da análise documental, efetivou-se um estudo de casos múltiplos, utilizando o método exploratório e descritivo. Para isso, foram selecionadas as IES que ofertavam a disciplina Empreendedorismo nos cursos de graduação em Administração e nos quais o coordenador de curso ou equivalente se dispôs a fornecer as informações necessárias para a realização da pesquisa, totalizando 12 dentre as 52 instituições existentes. Foi aplicado ainda um questionário com questões fechadas, abertas e semiabertas aos professores e coordenadores das IES. ${ }^{5}$

A pesquisa concluiu que o ensino do empreendedorismo estava presente nos cursos de Administração, mas estava voltado para a inserção no mercado de trabalho ao invés da abertura de um negócio próprio. Identificou igualmente que a ênfase do ensino de empreendedorismo estava na área negocial, e que a visão de empreendedorismo desses profissionais estava focada na inovação, criatividade e ação. Quanto às características fundamentais para o empreendedor, os profissionais apontaram a busca de oportunidade e iniciativa; persistência; propensão a correr riscos calculados; capacidade de persuadir e de estabelecer uma rede de contatos e de comprometimento.

Ao final, Silva (2010) recomendou que fossem realizadas pesquisas que focassem a metodologia utilizada na disciplina Empreendedorismo, assim como se examinasse se os docentes lidam com a adaptação dessas metodologias à realidade dos alunos e à localidade em que são ministradas.

O último trabalho apresentado nesta seção é a tese de doutorado de Ribas (2011, p. 11), cujo objetivo foi "[...] definir as diretrizes curriculares para elaborar programas de formação de empreendedores, com base na Escola Progressiva de John Dewey". O autor utilizou como estratégia de pesquisa a revisão da literatura, a pesquisa documental e a pesquisa de campo. Para construir os fundamentos epistemológicos da sua proposta, referiu ter se pautado, especialmente, pela Escola Progressiva de Dewey, assim como pela Escola do Profissional Reflexivo de Schön e pela Pedagogia da Autonomia de Paulo Freire.

Segundo Ribas (2011, p. 104), o objetivo do programa de formação apresentado "[...] é o de permitir que o participante desenvolva competência para realizar uma ação de empreender com sucesso e, com isso, adquirir autonomia no saber e no ser". Como consequência, ainda conforme o autor, "Prepara-se para ser um cidadão emancipado na sua condição econômica e social" (p. 103).

Cabe salientar que, assim como Pedro (2007), Ribas (2011, p. 98) também afirmou que o intuito do seu programa de formação não era apenas obter competência nas práticas de gestão, mas transformar o sujeito em um “[...] cidadão livre para decidir o seu próprio 
caminho". Vale lembrar que, para esses autores, tal "liberdade" é possibilitada pela educação para o empreendedorismo.

\section{O LADO OCULTO DA EDUCAÇÃO EMPREENDEDORA}

São descritas, nesta seção, as oito teses e dissertações, selecionadas no Banco de Teses da Capes, que apresentam uma perspectiva crítica sobre a educação voltada para o empreendedorismo. É importante destacar que dessas, sete foram desenvolvidas em Programas de Pós-Graduação em Educação.

O primeiro é uma dissertação de mestrado defendida por Carli (2000). Partindo da análise do Projeto Patinho Empreendedor, Carli (2000) construiu uma reflexão sobre as origens, especificidades e influências sociopolítico-econômicas do ensino de empreendedorismo no Brasil. O Projeto Patinho Empreendedor foi implantado na cidade de Pato Branco (PR), no ano de 1998, e estruturado pelo Sebrae, visando ao ensino do empreendedorismo para as crianças das séries iniciais do ensino fundamental da rede pública.

Para subsidiar sua reflexão, a autora analisou os sete volumes dos relatórios produzidos pela coordenadoria do projeto no Sebrae-PR e realizou entrevistas com as pessoas envolvidas (professores multiplicadores, diretores de escolas, secretária municipal de Educação, representante da equipe de ensino e coordenadores).

Feita a análise dos documentos, principalmente do conteúdo e da metodologia utilizados, Carli (2000) salientou que esse projeto, sob a capa da inovação, acaba sendo um instrumento para inculcar na mente das crianças valores propagados pela ideologia capitalista. Da mesma forma, ao separar planejadores/executores e transformar professores em facilitadores, devidamente treinados e presos às apostilas prontas, essa proposta de ensino acaba alienando o professor e ignorando as peculiaridades dos educandos. Assim, conforme a autora, o que se pôde perceber foi a aceitação, por parte da sociedade, desses discursos e práticas desenvolvidas de forma acrítica e apressada.

Também em uma dissertação de mestrado, Souza (2006), empregando uma pesquisa bibliográfica e documental, procurou refletir sobre $o$ discurso do empreendedorismo e o seu direcionamento aos jovens. Com esse objetivo, e apoiado teoricamente em Gramsci, o autor refez o caminho da construção desse discurso até a sua sintetização na conhecida expressão "jovem empreendedor".

Da mesma forma que os estudos que advogam em favor de uma educação voltada ao ensino do empreendedorismo, Souza (2006) enfatizou as mudanças ocorridas na economia mundial e as suas consequências, como a diminuição dos empregos formais. Contudo, não omitiu outras implicações (advindas desse processo), como os baixos salários, a ameaça aos direitos sociais já conquistados - rotulada de "flexibilização das relações trabalhistas" - e a falta de empenho por parte do Estado no desenvolvimento de políticas para a criação de emprego e renda.

Ao dialogar com Louis Jacques Filion, José Carlos de Assis Dornelas e, especialmente, Fernando Dolabela, Souza (2006) expôs os argumentos desses autores que difundem a educação empreendedora e, também, deixou em evidência o papel ativo dos organismos internacionais na construção e difusão dessa ideologia, em que a figura do "jovem" ocupa um lugar de destaque.

Para Souza (2006), contrariamente à imagem divulgada do jovem independente e realizado na sua profissão, a educação empreendedora tem por intuito construir um jovem 
adequado à realidade de trabalho marcada pela precariedade, sem direitos e garantias sociais, tornando-o responsável pelo seu ocasional "fracasso". Nas palavras do autor:

[...] a educação empreendedora é um discurso que, sob o argumento da realização do sonho e do sucesso pessoal e profissional, apresenta-se como a solução para o 'trabalho' do jovem, capaz de superar os desafios do desemprego e da pobreza. No entanto, concluiu-se que, dissimuladamente, seu resultado é a naturalização do jovem como um protagonista empreendedor, isto é, o único responsável tanto por seu emprego ou desemprego - e, desse modo, por sua sobrevivência - quanto pelo desenvolvimento econômico da coletividade a que pertence. Enfim, o discurso da educação do jovem para o empreendedorismo revelou-se, sobretudo, pragmático e ideológico, ao reforçar o individualismo próprio da racionalidade neoliberal (2006, p. 130).

De forma semelhante a Carli (2000), Souza (2006) chamou a atenção para a grande adesão das instituições educacionais de diferentes níveis e modalidades à educação empreendedora, que reproduzem em seus projetos tal ideologia sem, contudo, promover uma reflexão mais aprofundada sobre o assunto.

Pautado pelo método materialista histórico-dialético, Dias (2006), em sua dissertação de mestrado, teve por objetivo compreender a ideologia empreendedora na escola, enfocando a atuação do Sebrae, em um curso destinado aos alunos do ensino médio.

Para o autor, os discursos que envolvem noções, como competência, empregabilidade e o próprio empreendedorismo, foram utilizados pelas classes dominantes, a fim de atender às demandas da produção capitalista, tendo o Sebrae um lugar de destaque na disseminação dessas ideias, especialmente, em relação ao empreendedorismo.

Dias (2006, p. 96) tratou de reconstruir a história do Sebrae, para identificar a entrada do discurso empreendedor nessa instituição e procurou "[...] qualificar a concepção de homem e mundo que o ensino do empreendedorismo nas escolas, promove nos alunos".

Para alcançar o seu propósito, o autor analisou o curso do Sebrae, intitulado Programa de Formação de Jovens Empreendedores, oferecido às escolas públicas e privadas de ensino médio, o qual tem por objetivo disseminar a cultura empreendedora na sociedade. Enfocando a estrutura curricular e o material didático do curso, assinalou que o discurso do Sebrae aponta, como única saída para o desemprego (entendido como inevitável diante do avanço tecnológico), o aprimoramento dos "talentos" individuais, visando à sua adequação às "flutuantes" exigências do mercado:

[...] a personalidade do empreendedor incidirá diretamente no sucesso ou fracasso da nova empresa. Assim, a subjetividade tem fator decisivo para o empreendedor, o que ao nosso ver perfaz a concepção de competência. Nesta linha, os elementos subjetivos são postos como responsáveis pelo sucesso ou fracasso não levando em conta a realidade contraditória e historicamente produzida, o que espraia a perspectiva de responsabilidade individual sobre qualquer acontecimento no negócio do empreendedor, o que infere também em conceber o desemprego como falha individual ou indisposição de que quem não soube empreender (DIAS, 2006, p. 101). 
Dias (2006, p. 104) concluiu que a "pedagogia empreendedora" difundida pelo Sebrae tem como "[...] perspectiva histórica a adaptação do ser humano à sociedade capitalista, desconsiderando qualquer possibilidade de transformação radical deste modelo de sociedade".

Lima (2008), em sua dissertação de mestrado, entendeu que o discurso que sustenta o empreendedorismo vem de encontro à ideia de cooperação, ajuda mútua e autogestão, que fundamenta a prática da economia solidária e, dessa forma, tentou compreender esse discurso, propondo-se a:

[...] estudar as origens, os fundamentos e as condições favoráveis à disseminação do empreendedorismo no Brasil através de políticas sociais e educacionais e demonstrar como ele foi mitificado com a promessa de compensar os 'perdedores' da globalização, analisando os riscos que isto representa, em particular para os trabalhadores pobres na ampliação de sua vulnerabilidade (LIMA, 2008, p. 8).

Lima (2008) retornou às décadas de 1970 e 1980 para explicar como se construiu o ambiente marcado pelo desemprego da década de 1990 e que criou as condições necessárias para a difusão da ideologia empreendedora. Após refazer esse percurso, apontou para aquilo que denominou de "mitificação do empreendedorismo", que seria a transfiguração da necessidade dos trabalhadores de trabalhar e gerar renda em "motivação para empreender".

A mitificação do empreendedorismo é uma ameaça aos trabalhadores desempregados e informais, na medida que confere atributos atraentes e exagerados a uma proposta, visando a mascarar os efeitos nefastos da globalização capitalista que gera 'perdedores' (LIMA, 2008, p. 58).

Finalmente, o autor assinalou que é desafio da economia solidária superar a campanha em prol do empreendedorismo, bem como demonstrar que o trabalho associado não é incompatível com os direitos sociais dos trabalhadores.

Em sua tese de doutorado, Drewinski (2009) problematizou o discurso da educação empreendedora, analisando duas de suas propostas, o Projeto Jovem Empreendedor e a Pedagogia Empreendedora, enfocando suas similaridades e diferenças.

Conforme Drewinski (2009, p. 144), os dois projetos possuem objetivos, fins e metas distintos, já que o primeiro é voltado ao combate do desemprego juvenil, e o segundo tem como foco o empenho individual na busca da realização de "sonhos", tornando-se uma proposta "[...] descolada das condições materiais de existência do indivíduo".

Entretanto, para a autora, esses projetos se aproximam, uma vez que: a) tomam o desenvolvimento do protagonismo juvenil como uma forma de inserção econômico-social; b) estão voltados à formação de uma "cultura empreendedora"; e c) compartilham a mesma base teórica educacional - o "aprender a aprender" para concretizar o "aprender a empreender".

Por último, Drewinski (2009, p. 147) concluiu que, ao não explicitar as contradições da sociedade capitalista e nem propor formas para resolver os problemas atuais, os discursos que sustentam a educação empreendedora são ideológicos e conservadores, arrematando: "Em suma, o que figura na aparência do novo não é novo, mas converge e tem muita semelhança com o velho". 
Já a dissertação de mestrado de Almeida (2010) teve como objetivo discutir a construção de uma cultura empreendedora na cidade de Horizonte (CE), e sua entrada nos ambientes educativos da cidade (não apenas na escola, mas atuando por intermédio de vários dispositivos, como igrejas, ONGs, associações comunitárias, empresas).

Para embasar a sua análise, Almeida (2010, p. 10) utilizou, especialmente, o conceito de "governamentalidade" de Michel Foucault, que para ele "[...] constitui uma poderosa ferramenta, capaz de mostrar que elos existem entre a racionalidade neoliberal, $o$ exercício da autoridade e os tipos de conduta evidenciada pelos cidadãos".

Interessado em perceber esse processo na cidade de Horizonte, o autor analisou documentos e realizou entrevistas semiestruturadas com os secretários da Educação e do Desenvolvimento Econômico, visando a perceber quais discursos estavam sendo produzidos e seus respectivos efeitos na construção de uma nova maneira de conceber a educação.

Almeida (2010) concluiu que o projeto neoliberal de desenvolvimento da cidade de Horizonte apresenta-se como uma forma de agregar valor por meio de novas oportunidades de negócios e também pelo incentivo ao empreendedorismo, entendido como capaz de construir profissionais inovadores, empreendedores e cidadãos responsáveis.

Ao final, o autor salientou que, na atualidade, a educação vem sendo concebida como bem de mercado e a ampliação do discurso de valorização do indivíduo empreendedor acaba por contribuir para a manutenção da hegemonia do pensamento neoliberal.

O único trabalho, analisado nesta seção, defendido em uma área diferente da Educação (Psicologia), foi o de Lima Júnior (2011). Em sua dissertação de mestrado, Lima Júnior (2011, p. 17) afirmou que a cultura do empreendedorismo neoliberal atinge a subjetividade dos envolvidos e traz como consequência uma maior complexidade nas relações entre os sujeitos dentro das empresas e das escolas, "[...] abrindo espaço para formas de controle, fazendo com que surjam sintomas dos mais diversos, tais como, inibição afetiva, bloqueios, brigas, intrigas, ausência de comunicação e individualismos". Partindo desse ponto de vista, Lima Júnior (2011, p. 13) realizou uma pesquisa qualitativa, de tipo exploratória, cujos objetivos foram:

[...] i. compreender as bases dos valores e padrões econômicos que migram para os domínios da vida social, de forma especial nos processos de educação empreendedora, agenciando o educador, os educandos e todos os envolvidos indiretos; ii. repassar e criticar os fundamentos e princípios das abordagens da educação empreendedora do tipo funcionalista e não-emancipatória, enquanto linguagem hegemônica do empreendedorismo individualista e socialmente perverso; iii.verificar caminhos de resgate das idéias do empreendedorismo, enquanto educação emancipatória, crítica e solidária, fundamentada nos princípios da liberdade, em uma abordagem educativa por competências.

Após analisar as críticas à teoria do capital humano no campo educacional, sob diferentes perspectivas (doutrina marxiana, pressupostos sociológicos e argumentos foucaultianos), e discorrer sobre o ensino do empreendedorismo no contexto histórico brasileiro, Lima Júnior (2011) tentou responder ao seu terceiro objetivo, isto é, verificar possibilidades para um ensino do empreendedorismo como educação emancipatória, crítica e solidária. 
Nesse sentido, o ensino do empreendedorismo poderia avançar em conjunto com o empreendedorismo social, cuja abordagem retoma os princípios da autonomia e da economia solidária. Conforme Lima Júnior (2011, p. 133):

Parece-me que a lógica de condução para uma educação empreendedora com o traço social e solidário parece apontar para a importância de um novo equilíbrio entre adaptação e autonomia, entre o conhecimento e a prática, entre o individual e o social, entre a criatividade e a reprodução, entre o saber de si, de seus limites e seus diferenciais e o saber do outro. Uma educação integral será empreendedora a partir do momento em que promover o encontro e o diálogo da subjetividade, da cultura, do econômico e do social no espaço dos empreendimentos inovadores e sustentáveis.

Dessa forma, Lima Júnior (2011), diferentemente de Lima (2008), acredita na possibilidade de um ensino do empreendedorismo com traço social e altruísta, capaz de contribuir para a formação de cidadãos autônomos e solidários.

Por fim, a tese de doutorado apresentada por Coan (2011, p. 37) indicava como objetivo "[...] compreender as implicações epistemológicas, políticas e práticas decorrentes da incorporação do empreendedorismo pelo campo educacional, investigando seu caráter ideológico, principalmente, na formação de um novo perfil de trabalhador". Para visualizar os desdobramentos desse processo na prática, Coan (2011) observou duas experiências de ensino de empreendedorismo: o Projeto Nacional de Educação para o Empreendedorismo em Portugal (PNEE) e as práticas do Instituto Federal de Santa Catarina (IF-SC).

Coan (2011) embasou sua investigação nos pressupostos teóricos do materialismo histórico e dialético que, conforme o autor, permitem refletir e explicar a realidade, tornando possível a sua superação. A coleta de dados lidou com fontes documentais, da literatura da área, entrevistas e questionários. A pesquisa sobre o PNEE envolveu alunos, professores, gestores de escolas e responsáveis pelo projeto. Já no IF-SC, a pesquisa enfocou docentes e discentes (regulares e egressos).

É importante salientar que o terceiro capítulo da tese apresenta, além dos aspectos históricos da educação para o empreendedorismo, a discussão de alguns trabalhos (teses, dissertações, livros, artigos, entrevistas) que defendem esse projeto de educação, assim como de trabalhos que apontam críticas a essa proposta. Ao analisar tais trabalhos, Coan (2011) ratifica a percepção do desequilíbrio, já sublinhada no início deste artigo, entre a quantidade de produções de cunho apologético e de trabalhos críticos à proposta do ensino do empreendedorismo.

O autor concluiu que a educação para o empreendedorismo constrói um trabalhador/empreendedor cujas competências estão de acordo com as necessidades do mercado de trabalho globalizado, seja como empreendedor ao abrir o seu próprio negócio, seja como intraempreendedor, ao vender sua força de trabalho "flexível". Concluiu igualmente que a educação para o empreendedorismo pode ser entendida, ao mesmo tempo, como ideologia, propaganda e mercadoria que é vendida e comprada pelos sistemas de ensino de diversos países da rede privada ou pública de ensino. Resulta desse processo a "colonização do espaço escolar", isto é, a entrada dos discursos e práticas do mundo empresarial na escola, corporificados no próprio currículo, bem como em feiras de negócios, produção e comercialização de produtos ou confecção de plano de negócios. 
Finalmente, Coan (2011, p. 464) concorda com Drewinski (2009), quando afirmou que o discurso que embasa o ensino do empreendedorismo, embora tenha aparência de "novo", na verdade,

[...] não é tão atual uma vez que se encontra presente no pensamento dos clássicos da economia, como estratégias de consolidação do capitalismo e na atualidade continua a ser reverberação dos interesses dos donos do capital que se apropriam estrategicamente da escola para ser um dos canais de divulgação de seus novos/velhos interesses.

\section{REFLEXÕES SOBRE AS PROPOSIÇÕES DE UMA EDUCAÇÃO VOLTADA PARA O ENSINO DO EMPREENDEDORISMO}

[...] sessenta e duas mil repetições fazem uma verdade [...] Aldous Huxley (2003, p. 61).

Devido ao grande destaque que o empreendedorismo vem recebendo nas últimas décadas, pode-se perceber que inúmeras instituições escolares, em todos os seus diversos níveis e modalidades, "compraram" e estão propagando, mormente por meio dos seus currículos, o discurso que busca inculcar nos estudantes valores como autonomia, independência, competência, geração de riqueza e empregabilidade.

Apesar disso, atualmente, a integração do discurso em prol do empreendedorismo no cotidiano acadêmico começa, mesmo que vagarosamente, a ser debatida sob um ponto de vista mais crítico, demandando um olhar mais atento sobre a questão da educação associada às novas relações sociais e de trabalho.

Desde que a noção de currículo deixou de ser entendida apenas como uma forma de organização ou uma atividade, puramente, técnica e burocrática e, principalmente, imparcial, a escola não voltou mais a ser vista como um espaço neutro, mas, ao contrário, passou a ser compreendida como um local privilegiado para a reprodução da ideologia dominante. ${ }^{6}$

Nesse contexto, as reflexões propostas por Apple (1989, 2006), sobre os pressupostos que orientam a seleção dos saberes escolares, sempre resultados de disputas e conflitos, tornam-se um convite para se pensar o cenário atual de inserção do empreendedorismo no ambiente escolar.

A incorporação de noções, como flexibilidade, competência, individualidade, empregabilidade e empreendedorismo, na escola é dada, dentre outras formas, sobretudo, pelo currículo escolar, que é uma maneira de expressar intencionalidades, de caráter prático, político ou ideológico à sociedade. Por isso, ele se torna um aparelho poderoso e basilar para a conquista da hegemonia por parte da classe dominante.

Para Apple (1989), o conhecimento corporificado pelo currículo escolar é um conhecimento particular, que reflete, com frequência, compromissos ideológicos. Trata-se de um recurso empregado pelos grupos dominantes como esforço permanente de convencimento ideológico para manutenção da sua hegemonia. Esse convencimento, de acordo com o autor, atinge a sua máxima eficácia quando se transforma em senso comum, quando se naturaliza.

Esse parece, atualmente, ser o caso do empreendedorismo, que compartilha com os conceitos de empregabilidade e capital humano valores como individualidade, flexibilidade, competência, competitividade. Valores estes exigidos pelo mercado e que 
transformam o discurso a favor do empreendedorismo em algo tão comum que pouco se ousa criticá-lo.

Frigotto $(2004,2010)$ e Pochmann (2002) declaram que as concepções neoliberais incorporadas às políticas para a educação são artifícios para desmontar as conquistas e direitos sociais do trabalhador. Frigotto (2004) avança nas críticas, alegando que a pedagogia das competências e da empregabilidade (que possui parentesco com a ideologia do empreendedorismo) manifesta-se, nos planos pedagógico e cultural, como a nova forma de exploração do trabalho pela ideologia do capitalismo flexível.

Para Frigotto (2007, p. 1136), "[...] a profissionalização compulsória do ensino médio e a formação técnico-profissional [...]" estão inseridas na perspectiva de adestramento para o mercado. De acordo com esse autor, milhares de jovens e adultos trabalhadores são condenados a cursos profissionalizantes desprovidos de uma base científica, técnica e de cultura humana mais geral, que não preparam o sujeito nem para as exigências profissionais, nem para o exercício autônomo da cidadania.

A educação articulada ao mundo do trabalho, conforme Frigotto (2010), não deve ser confundida com um imediatismo tecnicista, produtivista e economicista. Ao contrário, deve ser vista como um direito social e subjetivo, pois permite entender criticamente o funcionamento e a constituição da sociedade humana e, também, o mundo da natureza do qual fazemos parte.

Diante disso, para Frigotto (2010, p. 77), o desafio seria:

Desconstruir, primeiramente, do imaginário das classes populares, o entulho ideológico imposto pelas classes dominantes da teoria do capital, da pedagogia das competências, da empregabilidade, do empreendedorismo e da idéia que cursinhos curtos profissionalizantes, sem uma educação básica de qualidade, os introduzem rápido ao emprego.

A afirmação de Frigotto (2010) vai ao encontro do pensamento gramsciano, que critica a finalidade da escola como preparação de mão de obra para o mercado de trabalho, isto é, uma escola "interessada". Conforme Gramsci (2011, p. 49),

$\mathrm{Na}$ escola atual, em função da crise profunda da tradição cultural e da concepção da vida e do homem, verifica-se um processo de progressiva degenerescência: as escolas de tipo profissional, isto é, preocupadas em satisfazer interesses práticos imediatos, predominam sobre a escola formativa, imediatamente desinteressada. $\mathrm{O}$ aspecto mais paradoxal reside em que este novo tipo de escola aparece e é louvado como democrático, quando, na realidade, não só é destinado a perpetuar as diferenças sociais, como ainda a cristalizá-las em formas chinesas.

Pode-se perceber que a escola tradicional, formativa, de cultura humanista e desinteressada, era estimada por Gramsci, em detrimento da escola profissionalizante, técnica e interessada. No entanto, consciente da crise da escola tradicional, Gramsci "[...] compreende e defende o surgimento de um novo tipo de escola mais orgânica ao mundo industrial" (NOSELLA, 2010, p. 166). Desse modo, ele sugere a organização de uma escola unitária, capaz de "[...] assumir a função de ingressar os indivíduos no processo de trabalho, sem, contudo, poder restringir-se a uma educação que forme exclusivamente para o trabalho [...]" (SOBRAL; MORAES; JIMENEZ, 2010, p. 91-92). 
Gramsci acreditava no poder libertador da escola, isto é, para ele a escola deveria estabelecer as bases para a construção de um projeto de sujeito emancipado por meio de sua autonomia intelectual, moral, racional. Assim, para Gramsci, é mister que se assuma como referência um princípio educativo "[...] que equilibre o desenvolvimento da capacidade de trabalhar manualmente (tecnicamente, industrialmente) com o desenvolvimento da capacidade de trabalho intelectual [...]" (MANACORDA, 2008, p. 265).

Com efeito, as proposições gramscianas vão de encontro ao discurso presente nas propostas de educação para o empreendedorismo, pois este, além de não romper com o modelo de produção capitalista e nem preparar o sujeito para o exercício da cidadania, sugere uma formação imediatista, que se reduz apenas ao adestramento do trabalhador para os interesses do mercado.

\section{CONSIDERAÇÕES FINAIS}

A retórica sedutora presente no discurso do empreendedorismo está cada vez mais forte em nossa sociedade, inclusive, nos últimos anos, no meio acadêmico. A promessa de independência, liberdade, autonomia, realização pessoal e felicidade parece ser atraente demais para não chamar a atenção.

Nesse cenário, percebe-se que a escola, em seus diversos níveis e modalidades, tem sofrido, em seus currículos, a invasão e influência de noções como competência, individualidade e empregabilidade, e esse quadro parece indicar que a lógica da educação está caminhando em direção unicamente à lógica de um mercado, que, cada vez mais, pretende prescindir do trabalhador.

O termo empreendedorismo e os conceitos que lhes foram atribuídos se tornaram tão pujantes que raros são os pesquisadores que têm o atrevimento para desafiá-los e levantar qualquer crítica a seu respeito, deixando, com isso, explícito que se trata de uma verdade inexorável, hegemônica.

Ratifica-se aqui a percepção inicial de que existe um grande número de teses e dissertações que defendem o ensino do empreendedorismo, e uma quantidade reduzida que critica essa posição. Evidencia-se que os trabalhos que advogam em benefício do ensino do empreendedorismo manifestam-se apenas a partir do lugar-comum, isto é, das alegações de promoção do crescimento econômico, geração de empregos e distribuição de renda, propostas por autores como Dornelas (2008), Dolabela $(1999,2008)$ e Chiavenato (2004), e acabam assumindo, ideologicamente, na maioria dos casos, a validade do conceito como um dogma, sem lidar com a tarefa do diálogo com aqueles outros que questionam os fundamentos sobre os quais assentam suas proposições.

Também não foram encontradas diferenças significativas na abordagem do tema nos trabalhos que defendem os benefícios de uma educação empreendedora, mesmo quando as pesquisas partiram de diferentes áreas do conhecimento. Foi possível verificar, igualmente, que os poucos trabalhos que procuram questionar tal discurso provêm, principalmente, da área de Educação.

Para os autores deste trabalho, o perigo reside, justamente, na ideia que metaboliza a educação para o empreendedorismo como (uma declaração) incontestável e provido de um discurso determinista fatalista.

Comunga-se, aqui, com o pensamento de Drewinski (2009, p. 147), quando alega que "[...] os discursos presentes nas propostas de educação empreendedora são ideológicos 
e conservadores porque não explicitam as contradições da sociedade capitalista e nem apontam formas de resolução dos problemas atuais".

Ademais, acredita-se que não basta conhecer, por exemplo, as aplicações e os objetivos, as causas e as consequências da educação para o empreendedorismo; é preciso avançar e debater possíveis formas de extrapolar a proposta de formação para o empreendedorismo, como sugerem Dias (2006) e Lima (2008), estabelecendo práticas educativas baseadas em uma concepção do existir humano para além do mercado.

\section{REFERÊNCIAS}

ALMEIDA, J. W. Governamentalidade neoliberal, empreendedorismo e suas repercussões nos processos educacionais da cidade de Horizonte-CE. 2010. $123 \mathrm{f}$. Dissertação (Mestrado em Educação) - Programa de Pós-Graduação em Educação Brasileira, Universidade Federal do Ceará, Fortaleza, 2010.

APPLE, M. W. Educação e poder. Porto Alegre: Artes Médicas, 1989.

Ideologia e currículo. 3. ed. Porto Alegre: Artmed, 2006.

BIRLEY, S; MUZYKA, D. F. Dominando os desafios do empreendedor. São Paulo: Makron Books, 2001.

CARLI, H. A. de. O ensino de empreendedorismo e o caso específico de Pato Branco: Projeto Patinho Empreendedor. 2000. 208 f. Dissertação (Mestrado em Educação) Programa de Pós-Graduação em Educação, Universidade Estadual Paulista "Júlio de Mesquita Filho", Marília, 2000.

CHIAVENATO, I. Empreendedorismo: dando asas ao espírito empreendedor. São Paulo: Saraiva, 2004.

COAN, M. Educação para o empreendedorismo: implicações epistemológicas, políticas e práticas. 2011. 540 f. Tese. (Doutorado em Educação) - Programa de Pós-Graduação em Educação, Universidade Federal de Santa Catarina, Florianópolis, 2011.

DIAS, G. P. Empreendedorismo e educação: o Sebrae na escola. 2006. 136 f. Dissertação (Mestrado em Educação) - Programa de Pós-Graduação em Educação, Universidade Federal Fluminense, Niterói, 2006.

DOLABELA, F. O segredo de Luísa. Rio de Janeiro: Sextante, 2008.

Oficina do empreendedor. 6. ed. São Paulo: Editora de Cultura, 1999.

DORNELAS, J. C. A. Empreendedorismo: transformando idéias em negócios. 3. ed. Rio de Janeiro: Elsevier, 2008.

DREWINSKI, J. M. de A. Empreendedorismo: o discurso pedagógico no contexto do agravamento do desemprego juvenil. 2009. 157 f. Tese (Doutorado em Educação) Programa de Pós-Graduação em Educação, Universidade Federal do Paraná, Curitiba, 2009. 
D’AlBERTO, A. M. F. O ensino do empreendedorismo nos cursos de Turismo do Estado de Santa Catarina, Brasil. 2005. 222 f. Dissertação (Mestrado em Administração) - Programa de Pós-Graduação em Administração, Universidade Regional de Blumenau, Blumenau, 2005.

FILION, L. J. O Empreendedorismo como tema de estudos superiores. Conferência feita no evento "A Universidade Formando Empreendedores". CNI-IEL Nacional. Brasília, 1999.

FRIGOTTO, G. A relação da educação profissional e tecnológica com a universalização da educação básica. Educação \& Sociedade, v. 28, n. 100, p. 1129-1152, out. 2007. Disponível em: <http://www.cedes.unicamp.br>. Acesso em: 25 jan. 2012.

Concepções e mudanças no mundo do trabalho e o ensino médio. In: FRIGOTTO, G.; CIAVATTA, M.; RAMOS, M. (Org.). Ensino médio integrado. 2. ed. São Paulo: Cortez, 2010.

Juventude, trabalho e educação no Brasil: perplexidades, desafios e perspectivas. In: NOVAES, R.; VANNUCHI, P. (Org.). Juventude e sociedade: trabalho, educação, cultura e participação. São Paulo: Editora Fundação Perseu Abramo, 2004.

GRAMSCI, A. Cadernos do cárcere: introdução ao estudo da filosofia: a filosofia de Benedetto Croce. 5. ed. Rio de Janeiro: Civilização Brasileira, 2011. v. 1.

Concepção dialética da história. Tradução de Carlos Nelson Coutinho. 3. ed. Rio de Janeiro: Civilização Brasileira, 1978.

HUXLEY, A. Admirável mundo novo. 2. ed. São Paulo: Globo, 2003.

KOHN, A. Punidos pelas recompensas: os problemas causados por prêmios por produtividade por produtividade, planos de incentivos, remuneração variável, elogios, participação nos lucros e outras formas de suborno. São Paulo: Atlas, 1998.

LEAL, A. F. Aprender a empreender: um pilar na educação de jovens e adultos. 2009. 145 f. Dissertação (Mestrado em Educação) - Programa de Pós-Graduação em Educação, Universidade Federal da Paraíba, João Pessoa, 2009.

LIMA, A. L. de. Os riscos do empreendedorismo: a proposta de educação e formação empreendedora. 2008. 131 f. Dissertação (Mestrado em Educação) - Programa de PósGraduação em Educação, Universidade de São Paulo, São Paulo, 2008.

LIMA JÚNIOR, O. P. A. de. O espírito do capitalismo e a cultura do empreendedorismo: educação e ideologia. 2011. 141 f. Dissertação (Mestrado em Psicologia) - Programa de Pós-Graduação em Psicologia, Pontifícia Universidade Católica de Minas Gerais, Belo Horizonte, 2011.

MANACORDA, M. A. Marx e a pedagogia moderna. Campinas: Alínea, 2008.

MAXIMIANO, A. C. A. Administração para empreendedores: fundamentos da criação e da gestão de novos negócios. São Paulo: Pearson Prentice Hall, 2006. 
MIRSHAWKA, V.; MIRSHAWKA Jr., V. Gestão criativa: aprendendo com os empreendedores mais bem-sucedidos do mundo. São Paulo: DVS Editora, 2003.

NEVES, E. O. Educação e empreendedorismo: um estudo sobre a formação empreendedora no curso Técnico em Agropecuária do Instituto Federal de Educação, Ciência e Tecnologia do Norte de Minas Gerais. 2010. 69 f. Dissertação (Mestrado em Educação Agrícola) - Instituto de Agronomia, Universidade Federal Rural do Rio de Janeiro, Seropédica, RJ, 2010.

NOSELLA, P. A escola de Gramsci. 2. ed. São Paulo: Cortez, 2010.

PAVANI, P. O. de C. A inclusão dos princípios fundamentais do empreendedorismo no Curso Técnico em Agroindústria da Escola Agrotécnica Federal de Barbacena. 2006. 56 f. Dissertação (Mestrado em Ciências) - Programa de Pós-Graduação em Educação Agrícola, Universidade Federal Rural do Rio de Janeiro, Seropédica, 2006.

PEDRO, A. M. Procedimentos para integrar os conceitos de empreendedorismo no ensino fundamental. 2007. 125 f. Tese. (Doutorado em Engenharia de Produção) Programa de Pós-Graduação em Engenharia de Produção, Universidade Federal de Santa Catarina, Florianópolis, 2007.

POCHMANN, M. O trabalho sob fogo cruzado: exclusão, desemprego e precarização no final do século. 3. ed. São Paulo: Contexto, 2002.

RIBAS, R. O saber empreendedor: diretrizes curriculares para elaboração de programas para formação de empreendedores com base na Escola Progressiva de John Dewey: reflexão e proposta. 2011. 172 f. Tese. (Doutorado em Educação) - Programa de PósGraduação em Educação, Pontifícia Universidade Católica de São Paulo, São Paulo, 2011.

SENNA, M. A. B. A associação do ensino agrícola ao desenvolvimento de comportamentos empreendedores no Instituto Federal do Espírito Santo - Campus de Alegre. 2010. 70 f. Dissertação (Mestrado em Educação Agrícola) - Instituto de Agronomia. Universidade Federal Rural do Rio de Janeiro, Seropédica, RJ. 2010.

SILVA, G. S. da. Educação empreendedora nas IES cearenses: um estudo multicaso. 2010. 120 f. Dissertação (Mestrado em Administração) - Programa de Pós-Graduação em Administração, Universidade de Fortaleza, Fortaleza, 2010.

SOBRAL, K. M.; MORAES, B. M.; JIMENEZ, M. S. V. Escola unitária e princípio educativo em Gramsci: um ensaio de compreensão à luz do Caderno 12. Filosofia e Educação (on-line), v. 2, n. 1, p. 83-100, abr./set. 2010. Disponível em: <http://www.fae. unicamp.br/revista/index.php/rfe/article/view/961>. Acesso em: 13 fev. 2012.

SOUZA, A M e. Jovens e educação empreendedora: que discurso é esse? 2006. $136 \mathrm{f}$. Dissertação (Mestrado em Educação) - Universidade Católica de Goiás, Goiânia, 2006. 


\section{Notas:}

${ }^{1}$ Email: marcelopandolfi@ifes.edu.br

${ }^{2}$ Email: relopes@ufscar.br

${ }^{3}$ Como na questão $\mathrm{n}^{\circ} 4$ : "Investir no mercado produtor através dos princípios empreendedores, aliados às qualidades técnicas operacionais, viabilizaria a inserção dos técnicos em agroindústria no sistema agroindustrial?" (PAVANI, 2006, p. 51).

${ }^{4}$ Mais interessante do que buscar a priori no empreendedorismo a solução para a entrada desses egressos no mercado agroindustrial seria investigar o motivo pelo qual o mercado não está absorvendo essa mão de obra, situação que pode estar, ou não, relacionada com o tipo de formação recebida por esses estudantes.

${ }^{5}$ Esse instrumento divide-se em três partes: a primeira busca traçar o perfil desses respondentes, em seguida, investiga as visões desses profissionais sobre o empreendedorismo e, por fim, quanto ao ensino do empreendedorismo.

${ }^{6}$ Deve-se ressaltar que a escola não é apenas um veículo de reprodução, mas também pode ser entendida como um espaço de contestação onde a resistência explícita ou sub-reptícia se faz presente (APPLE, 1989).

Recebido: Fevereiro-2013

Aprovado: Março-2013 